\title{
Dietary Patterns and Their Association with Depression among Type 2 Diabetes Patients in Gaza Strip, Palestine
}

\author{
Abdel Hamid el Bilbeisi1,2,3*, Mohammed Srour ${ }^{2}$, Amany el Afifi, \\ Halgord Ali M. Farag3,5, Kurosh Djafarian ${ }^{3}$ \\ ${ }^{1}$ Department of Clinical Nutrition, Faculty of Pharmacy, Al Azhar University of Gaza, Gaza Strip, Palestine \\ ${ }^{2}$ Department of Nutrition, Medicine \& Health Sciences College, University of Palestine, Gaza Strip, Palestine \\ ${ }^{3}$ Department of Clinical Nutrition, School of Nutritional Sciences and Dietetics, Tehran University of Medical Sciences, \\ International Campus (TUMS- IC), Tehran, Iran \\ ${ }^{4}$ Faculty of Pharmacy, Al Azhar University of Gaza, Gaza Strip, Palestine \\ ${ }^{5}$ Halabja Technical Institute, Sulaimani Polytechnic University, Kurdistan, Iraq \\ Email: ^Abed_az@hotmail.com
}

How to cite this paper: el Bilbeisi, A.H., Srour, M., el Afifi, A., Farag, H.A.M. and Djafarian, K. (2019) Dietary Patterns and Their Association with Depression among Type 2 Diabetes Patients in Gaza Strip, Palestine. Food and Nutrition Sciences, 10, 533-550.

https://doi.org/10.4236/fns.2019.105039

Received: March 31, 2019

Accepted: May 13, 2019

Published: May 16, 2019

Copyright $\odot 2019$ by author(s) and Scientific Research Publishing Inc. This work is licensed under the Creative Commons Attribution International License (CC BY 4.0).

http://creativecommons.org/licenses/by/4.0/

\begin{abstract}
Background: Depression is a common mental disorder. Globally, more than 340 million people of all ages suffer from depression. The aim of our study was to determine the association between major dietary patterns and depression among type 2 diabetes patients. Methods: This cross-sectional study was conducted among 480 type 2 diabetes patients attending primary healthcare centers in Gaza Strip, Palestine. The depression, anxiety, stress scales (DASS, 21-items) questionnaire was used to measure the score of depression. The participants' demographic, socioeconomic and medical history data was collected and the 98-items semi-quantitative food frequency questionnaire was used for evaluating the dietary patterns. Statistical analysis was performed using SPSS version 20. Results: Based on depression scale, 29.0\% of type 2 diabetes patients had depression, (58.3\% females, and $41.7 \%$ males). The prevalence of mild, moderate, severe, and very severe depression was $11.7 \%$, $8.5 \%, 6.7 \%$, and $2.1 \%$, respectively. Furthermore, two major dietary patterns were identified by factor analysis: The Western, and the grains-vegetables, and fruits patterns. After adjusting for the potential confounders, patients in the lowest tertile (T1) of the grains-vegetables, and fruits dietary pattern had a lower odds for depression (OR $0.76395 \%$ CI (0.667 - 0.871), $\mathrm{P}$ value $=0.001$ ); where as a higher odds for healthy (OR $1.44395 \%$ CI (1.131 - 1.839), P value $=0.004)$, compared to those in the highest tertile (T3). Conclusion: The grains-vegetables, and fruits dietary pattern may be associated with a lower prevalence of depression, and has been shown to be the healthiest dietary
\end{abstract}


pattern among type 2 diabetes patients.

\section{Keywords}

Depression, Dietary Patterns, Factor Analysis, Prevalence, Type 2 Diabetes Mellitus

\section{Background}

Depression is a common illness worldwide, with more than 340 million people of all ages suffering from depression [1]. Women are more affected by depression than men [2]. Depression is the leading cause of disability worldwide, and is a major contributor to the overall global burden of disease [3]. Especially when long-lasting and with moderate or severe intensity, depression may become a serious health condition [3]. In Palestine, psychological distress is high, quality of life is very low, and daily life of Palestinians is constantly under threat which makes Palestinians more vulnerable to stress and depression [4]. Depression is considered as an independent predictor for the onset of diabetes mellitus (DM) [5]. In addition, individuals with DM have been reported as having a higher prevalence of depression compared to those without the condition [6]. Furthermore, the odds for experiencing depressive symptoms in DM patients is two times more than nondiabetic persons, independent of sex, type of DM, subject source, or assessment method for depression [7]. However, depression has been approximately unrecognized and untreated in two-thirds of DM patients, which may lead to worsened DM complications [8]. In recent years, researchers have posited that there is a bidirectional link between depression and DM [9].

DM is a metabolic disease characterized by hyperglycemia resulting from defects in insulin secretion, insulin action or both [10]. Globally, the World Health Organization estimates that, 422 million adults were living with DM in 2014, and projects that DM will be the seventh leading cause of death in 2030 [11]. Most of DM deaths (More than 80\%) occur in low and middle-income countries [12]. In fact, the majority of people with DM are affected by type 2 DM (T2DM) [10]. In Palestine, the prevalence rate of DM was $10.5 \%$ in the West Bank and $11.8 \%$ in the Gaza Strip among the registered Palestinian refugees [13]. Abu Rmeileh et al. [14], estimated the prevalence of DM in Palestine at $20.8 \%$ and $23.4 \%$ in 2020 and 2030, respectively.

Dietary patterns are an approach that has been used to investigate diet-disease relations [15] [16]. Dietary pattern is potentially useful in making dietary recommendations because overall dietary patterns might be easy for the public to interpret or translate into diets [17]. In fact, patients with both DM and depression have low adherence to diet and exercise instructions, which may contribute to the worsening of their quality of life and the deterioration of their DM [18]. Diet is one of the lifestyle factors that may play an important role in preventing and managing these conditions [19] [20]. However, few studies have explored 
the relationship between dietary patterns and depression among T2DM patients. Most studies have examined the associations between individual foods or food groups and nutrients and depression [21] [22], instead of focusing on dietary patterns which is the most sensible approach to test the role of the overall diet on nutrition-related diseases. Therefore, understanding the association between dietary patterns with depression may be helpful in reducing diabetes-related premature mortality and improve outcomes among T2DM patients. To the best of our knowledge, this is the first study, which examined this association among T2DM patients in Gaza Strip, Palestine. Our study was conducted to identify major dietary patterns among T2DM patients and its association with depression.

\section{Material and Methods}

Study population: This cross-sectional study was conducted in the years 2017 and 2018, among a representative sample of Palestinian T2DM patients, selected by a cluster random sampling method. A total of 480 patients, aged 20 to 64 years attending primary healthcare centers (PHCs) in Gaza Strip, Palestine, were included in the study. Gaza Strip is divided into five smaller governorates. The total number of PHCs in Gaza Strip is fifty-four [23]. The PHCs were distributed in each governorate as follows (Eight, fourteen, sixteen, eleven and five PHCs respectively). The study sample was distributed according to the number of PHCs in each governorate as follows $(71,124,142,98$ and 45 patients respectively). Pregnant, lactating women and patients with other types of serious illness such as cancer or acute myocardial infarction were excluded from the study.

Assessment of dietary patterns: Data about dietary patterns was obtained using a validated semi-quantitative food frequency questionnaire (FFQ). The FFQ in our study contains a list of 98 food items; it was developed and validated among Palestinian population in 2014 [24]. All participants were asked to estimate the number of times per day, week or month he/she consumed these particular food products and the amount usually eaten per food item by making comparisons with the specified reference portion. The answer categories ranged from one to seven times including never, one to three times per month, one to two times per week, three to four times per week, five to six times per week, one time per day or two to three times per day. Dietary intakes were converted into grams per day. In addition, dietary patterns were obtained using factor analysis after the classification of food items into 25 groups [12].

Assessment of depression status: The depression, anxiety, stress scales (DASS, 21-items) questionnaire was used to measure the score of depression [25]. In the short form of the DASS questionnaire, for each subscale of depression, anxiety and stress, seven questions have been presented. Participants responded to each question based on to what extent that item applied to them during the last week. The answer categories ranged from zero to three times (Four categories) including did not apply to me at all, applied to me to some de- 
gree or some of the time, applied to me to a considerable degree or a good part of time, and applied to me very much or most of the time, respectively. The scores on the DASS-21 were multiplied by two to calculate the final score. Based on the total score of depression, the patients were divided into five groups: Normal (0 - 9), mild depression (10 - 13), moderate depression (14 - 20), severe depression (21 - 27), and very severe depression (28+). Finally, we divided all patients into two groups: Healthy (Depression scale, 7 -items scores $<10$ ), and depressed (Depression scale, 7-items scores $\geq 10$ ) [26].

Assessment of anthropometric measurements: Height (m), weight $(\mathrm{kg})$, and waist circumference (WC) were measured according to standard [27]. In addition, the body mass index (BMI) was calculated by dividing weight in kilograms by the square of height in meters.

Assessment of other variables: Additional information regarding demographic, socioeconomic and medical history variables was obtained with an interview-based questionnaire. Furthermore, data on physical activity was collected using the international physical activity questionnaire (IPAQ short version) [23]. Pilot study was carried out on thirty patients to enable the researcher to examine the tools of the study. The questionnaire and data collection process were modified according to the result of the pilot study. The data was collected by ten qualified data collectors (Five nurses and five nutritionists), who were given a full explanation and training by the researcher about the study.

Statistical analysis: All statistical analysis was performed using SPSS version 20. In our study, the major dietary patterns were obtained by factor analysis after classification of the 98 food items in the FFQ into 25 food groups [12]. The food grouping was based on the similarity of nutrient profiles and was somewhat similar to that used in previous studies [28] [29]. A varimax rotation was used, factor loads under 0.2 were excluded [30]. For determining the number of factors, we considered eigenvalues $>1$, the scree plot, and the interpretability of the factors. The adequacy of data was evaluated based on the value of Kaiser-Meyer-Olkin and Bartlett's test. In the present study, the Kaiser-Mayer-Olkin coefficient, was calculated and the obtained value was 0.719 . Then, the obtained dietary patterns scores are expressed as tertiles. The chi-square test was used to determine the significant differences between different categorical variable. The differences between mean were tested by independent samples t-test and one-way ANOVA. Finally, the odds ratio (OR) and confidence interval (CI) for the depression scale across tertiles categories of dietary pattern scores were tested by binary logistic regression. $\mathrm{P}$ value less than 0.05 was considered as statistically significant.

\section{Results}

A total of 480 patients with T2DM aged 20 to 64 years old (59.8\% females, $40.2 \%$ males) were included in present study. The characteristics of the study population by sex are shown in Table 1 . The findings of this study revealed that the 
Table 1. Characteristics of the study population by sex.

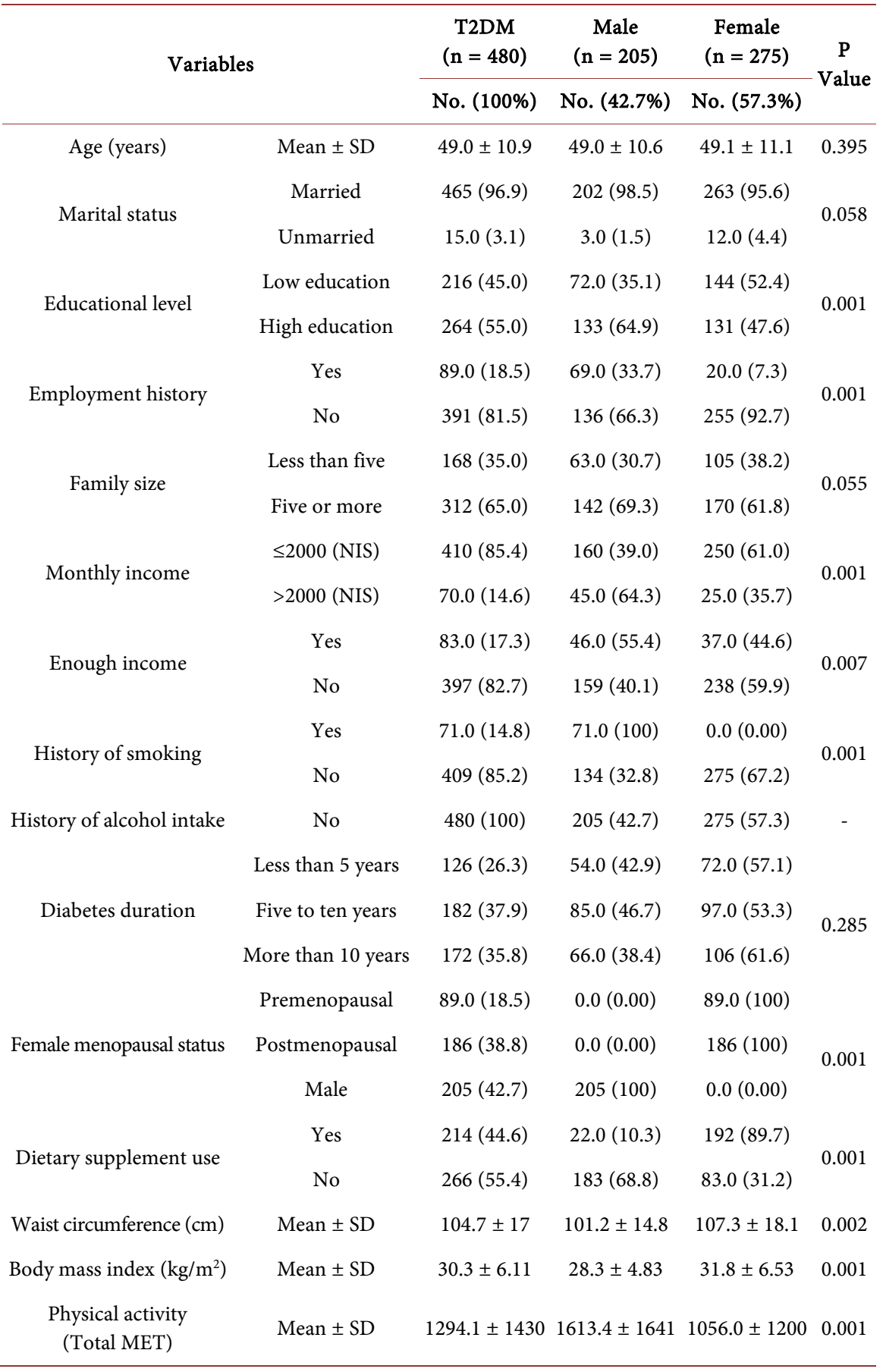

Data are expressed as means \pm SD for continuous variables and as percentage for categorical variables. The differences between means were tested by using independent sample $t$ test. The chi-square test was used to examine differences in the prevalence of different categorical variable. P value less than 0.05 was considered as statistically significant. SD, stander deviation.

mean age (years) for male patients was $49.0 \pm 10.6$ vs. $49.1 \pm 11.1$ for females. In addition, for the following variables (Educational level, employment history, monthly income, enough income, history of smoking, female menopausal status, dietary supplement use, WC, BMI, and physical activity level (Total MET)), the 
difference was statistically significant in both sexes ( $\mathrm{P}$ value $<0.05)$. With respect to depression scale, Table 2 shows that $29.0 \%$ of T2DM patients had depression (58.3\% females, $41.7 \%$ males). The prevalence of mild, moderate, severe, and very severe depression among T2DM patients was $11.7 \%, 8.5 \%, 6.7 \%$, and $2.1 \%$, respectively. Furthermore, for severe depression the difference was statistically significant in both sexes ( $\mathrm{P}$ value $=0.038$ ). Then, we entered food consumption data for the 25 food groups [12], into the SPSS for factor analysis. Table 3 shows the scree plot of eigenvalues, which indicated two major patterns: 1) The Western dietary pattern characterized by a high intake of refined grains, red meat, organ meat, fast foods, eggs, high-fat dairy products, hydrogenated fats, sugar, sweets \& desserts, snacks, and soft drinks as well as a low intake of beans and legumes; 2) The grains-vegetables, and fruits dietary pattern characterized by a high intake of whole grains, potatoes, vegetables, tomatoes, fruits, vegetable oils, olive, and beverages. The factor loading matrixes for the two major patterns are shown in Table 3. These two major dietary patterns explained $13.3 \%$ and $22.8 \%$ of the total variance, respectively. In the present study, the dietary patterns scores were classified as tertiles. Then, the characteristics of the study population were evaluated within the tertiles. Table 4 shows that patients in the lowest tertile (T1) of the grains-vegetables, and fruits dietary pattern were younger (46.91 \pm 11.2 vs. $50.34 \pm 9.87$ years, $\mathrm{P}$ value $<0.05)$, had low educational level $(37.0 \%$ vs. $27.8 \%$, P value $<0.001)$, had low monthly income $(33.6 \%$ vs. $33.2 \%$, P value < 0.001 ), were premenopausal (37.2 vs. 29.1 , P value $<0.05$ ), had a lower WC $(101.9 \pm 17.1$ vs. $106.6 \pm 17.4 \mathrm{~cm}, \mathrm{P}$ value $<0.001)$, had a lower BMI $(29.44 \pm 6.2$ vs. $30.85 \pm 6.1 \mathrm{~kg} / \mathrm{m}^{2}, \mathrm{P}$ value $<0.05$ ), and were more frequently physically active $(1487.2 \pm 1567$ vs. $1173.0 \pm 1276$ Total MET, P value $<0.001)$ compared to those in the highest tertile (T3). On the other hand, the distribution of patients with regard to age, monthly income, enough income, history of smoking, diabetes duration, female menopausal status, WC, BMI, and physical activity (Total MET) was significantly different across the tertiles of the Western dietary pattern ( $\mathrm{P}$ value $<0.05$ for all). Finally, we computed the OR and CI for the depression scale across tertiles categories of dietary patterns scores (Table 5). Our findings demonstrate that, after adjustment for confounding variables, patients in the lowest tertile (T1) of the grains-vegetables, and fruits dietary pattern characterized by a high intake of whole grains, potatoes, vegetables, tomatoes, fruits, vegetable oils, olive, and beverages had a lower odds for depression (OR 0.763 95\% CI (0.667 - 0.871), P value $=0.001)$; where as a higher odds for healthy (OR $1.44395 \%$ CI $(1.131-1.839)$, P value $=0.004)$, compared to those in the highest tertile (T3). No significant association was found between the Western dietary pattern with depression.

\section{Discussion}

Depression is the leading cause of disability worldwide, and is a major contributor to the overall global burden of disease [1]. In addition, individuals with DM 
Table 2. The depression scale for the study population by sex.

\begin{tabular}{|c|c|c|c|c|c|}
\hline \multirow{2}{*}{\multicolumn{2}{|c|}{ Variables }} & $\begin{array}{c}\text { T2DM } \\
(n=480)\end{array}$ & $\begin{array}{c}\text { Male } \\
(\mathrm{n}=205)\end{array}$ & $\begin{array}{c}\text { Female } \\
(\mathrm{n}=275)\end{array}$ & \multirow{2}{*}{$\begin{array}{c}P \\
\text { Value }\end{array}$} \\
\hline & & No. $(100 \%)$ & $\begin{array}{c}(\mathrm{n}=205) \\
\text { No. }(42.7 \%)\end{array}$ & $\frac{(\mathrm{n}=275)}{\text { No. }(57.3 \%)}$ & \\
\hline \multirow{4}{*}{$\begin{array}{l}\text { I couldn't seem to experience any } \\
\text { positive feeling at all }\end{array}$} & $(0)$ & $238(49.6)$ & $105(44.1)$ & $133(55.9)$ & \multirow{5}{*}{0.879} \\
\hline & (1) & $182(37.9)$ & $74.0(40.7)$ & $108(59.3)$ & \\
\hline & (2) & $47.0(9.8)$ & $21.0(44.7)$ & $26.0(55.3)$ & \\
\hline & (3) & $13.0(2.7)$ & $5.0(38.5)$ & $8.0(6105)$ & \\
\hline \multirow{4}{*}{$\begin{array}{l}\text { I found it difficult to work up the } \\
\text { initiative to do things }\end{array}$} & (0) & $236(49.2)$ & $103(43.6)$ & $133(56.4)$ & \\
\hline & (1) & $192(40.0)$ & $76.0(39.6)$ & $116(60.4)$ & \multirow{3}{*}{0.460} \\
\hline & (2) & $44.0(9.2)$ & $23.0(52.3)$ & $21.0(47.7)$ & \\
\hline & (3) & $8.0(1.7)$ & $3.0(37.5)$ & $5.0(62.5)$ & \\
\hline \multirow{4}{*}{$\begin{array}{l}\text { I felt that I had nothing to look } \\
\text { forward to }\end{array}$} & (0) & $270(56.3)$ & $118(43.7)$ & $152(56.3)$ & \multirow{4}{*}{0.353} \\
\hline & (1) & $160(33.3)$ & $62.0(38.8)$ & $98.0(61.2)$ & \\
\hline & (2) & $49.0(10.2)$ & $25.0(51.0)$ & $24.0(49.0)$ & \\
\hline & (3) & $1.0(0.2)$ & $0.0(0.0)$ & $1.0(100)$ & \\
\hline \multirow{4}{*}{ I felt down-hearted and blue } & $(0)$ & $319(66.5)$ & $136(42.6)$ & $183(57.4)$ & \multirow{4}{*}{0.513} \\
\hline & (1) & $114(23.8)$ & $47.0(41.2)$ & $67.0(58.8)$ & \\
\hline & $(2)$ & $45.0(9.4)$ & $22.0(48.9)$ & $23.0(51.1)$ & \\
\hline & (3) & $2.0(0.4)$ & $0.0(0.0)$ & $2.0(100)$ & \\
\hline \multirow{4}{*}{$\begin{array}{l}\text { I was unable to become } \\
\text { enthusiastic about anything }\end{array}$} & $(0)$ & 345 (71.9) & $143(41.4)$ & $202(58.6)$ & \multirow{4}{*}{0.560} \\
\hline & (1) & $90.0(18.8)$ & $40.0(44.4)$ & $50.0(55.6)$ & \\
\hline & $(2)$ & $41.0(8.5)$ & $21.0(51.2)$ & $20.0(48.8)$ & \\
\hline & (3) & $4.0(0.8)$ & $1.0(25.0)$ & $3.0(75.0)$ & \\
\hline \multirow{4}{*}{$\begin{array}{l}\text { I felt I wasn't worth much as a } \\
\text { person }\end{array}$} & $(0)$ & $352(73.3)$ & $153(43.5)$ & $199(56.5)$ & \multirow{4}{*}{0.770} \\
\hline & (1) & $93.0(19.4)$ & $39.0(41.9)$ & $54.0(58.1)$ & \\
\hline & $(2)$ & $34.0(7.1)$ & $13.0(38.2)$ & $21.0(61.8)$ & \\
\hline & (3) & $1.0(0.2)$ & $0.0(0.0)$ & $1.0(100)$ & \\
\hline \multirow{4}{*}{ I felt that life was meaningless } & $(0)$ & $391(81.5)$ & $168(43.0)$ & $223(57.0)$ & \multirow{4}{*}{0.910} \\
\hline & (1) & $76.0(15.8)$ & $31.0(40.8)$ & $45.0(59.2)$ & \\
\hline & $(2)$ & $13.0(2.7)$ & $6.0(46.2)$ & $7.0(53.8)$ & \\
\hline & (3) & $0.0(0.0)$ & $0.0(0.0)$ & $0.0(0.0)$ & \\
\hline \multicolumn{6}{|c|}{ Depression scale (7-items) multiplied by two } \\
\hline Total scores for depression scale & Mean \pm SD & $6.41 \pm 7.85$ & $6.41 \pm 7.89$ & $6.41 \pm 7.83$ & 0.584 \\
\hline Healthy & $\mathrm{DS}<10$ & $341(71.0)$ & $147(43.1)$ & $194(56.9)$ & \multirow{2}{*}{0.431} \\
\hline Depressed & $\mathrm{DS} \geq 10$ & $139(29.0)$ & $58.0(41.7)$ & $81.0(58.3)$ & \\
\hline Mild depression & DS $10-13$ & $56.0(11.7)$ & $20.0(35.7)$ & $36.0(64.3)$ & 0.163 \\
\hline Moderate depression & DS $14-20$ & $41.0(8.5)$ & $17.0(41.5)$ & $24.0(58.5)$ & 0.501 \\
\hline Severe depression & DS $21-27$ & $32.0(6.7)$ & $19.0(59.4)$ & $13.0(40.6)$ & 0.038 \\
\hline Very severe depression & DS $28+$ & $10.0(2.1)$ & $2.0(20.0)$ & $8.0(80.0)$ & 0.125 \\
\hline \multicolumn{6}{|c|}{$\begin{array}{l}\text { Data are expressed as means } \pm \text { SD for continuous variables and as percentage for categorical variables. The } \\
\text { differences between means were tested by using independent sample } t \text { test. The chi-square test was used to } \\
\text { examine differences in the prevalence of different categorical variable. P value less than } 0.05 \text { was considered } \\
\text { as statistically significant. DS: depression scale; SD: stander deviation; (0): Did not apply to me at all; (1): } \\
\text { Applied to me to some degree, or some of the time; (2): Applied to me to a considerable degree or a good } \\
\text { part of time; (3): Applied to me very much or most of the time. }\end{array}$} \\
\hline
\end{tabular}


Table 3. Factor loading matrix for major dietary patterns.

\begin{tabular}{|c|c|c|}
\hline \multirow{2}{*}{ Food Groups } & \multicolumn{2}{|r|}{ Dietary patterns } \\
\hline & The Western pattern & The grains-vegetables, and fruits pattern \\
\hline Refined grains & 0.659 & - \\
\hline Whole grains & - & 0.477 \\
\hline Potatoes & - & 0.307 \\
\hline Beans and legumes & 0.313 & 0.383 \\
\hline Red meat & 0.633 & - \\
\hline Organ meat & 0.369 & - \\
\hline Poultry & - & - \\
\hline Fish and shellfish products & - & - \\
\hline Fast foods & 0.427 & - \\
\hline Eggs & 0.486 & - \\
\hline Low-fat dairy product & - & - \\
\hline High-fat dairy products & 0.475 & - \\
\hline Vegetables & - & 0.654 \\
\hline Tomatoes & - & 0.450 \\
\hline Fruits & - & 0.604 \\
\hline Hydrogenated fats & 0.542 & - \\
\hline Vegetable oils & - & 0.602 \\
\hline Olive & - & 0.430 \\
\hline Nuts and seed products & - & - \\
\hline Sugar, sweets, and desserts & 0.428 & - \\
\hline Snacks & 0.438 & - \\
\hline Condiments & - & - \\
\hline Soft drinks & 0.474 & - \\
\hline Beverages & - & 0.353 \\
\hline Salt and pickles & - & - \\
\hline Variance explained (\%) & 13.360 & 22.854 \\
\hline
\end{tabular}

Values less than 0.2 were omitted for simplicity. Total variance explained by two factors: $\mathbf{3 6 . 2 1 4}$

have been reported as having a higher prevalence of depression compared to those without the condition [7]. To the best of our knowledge, this is the first study which describes the dietary patterns among T2DM patients and its association with depression in Gaza Strip, Palestine. Our findings demonstrate that, based on the depression, anxiety, stress scales (DASS, 21-items), 29.0\% of T2DM patients had depression, (58.3\% females, and $41.7 \%$ males). Furthermore, the prevalence of mild, moderate, severe, and very severe depression was $11.7 \%$, $8.5 \%, 6.7 \%$, and $2.1 \%$, respectively. In Palestine, psychological distress is high, 
Table 4. Characteristics and dietary intakes of study population by Tertile (T) categories of dietary pattern scores.

\begin{tabular}{|c|c|c|c|c|c|c|c|c|}
\hline \multirow{2}{*}{ Variables } & \multicolumn{3}{|c|}{ The Western pattern } & \multirow{2}{*}{$\begin{array}{c}\mathbf{P} \\
\text { Value }\end{array}$} & \multicolumn{3}{|c|}{ The grains-vegetables, and fruits pattern } & \multirow{2}{*}{$\begin{array}{c}\text { P } \\
\text { Value }\end{array}$} \\
\hline & $\mathrm{T} 1$ & $\mathrm{~T} 2$ & T3 & & $\mathrm{T} 1$ & $\mathrm{~T} 2$ & T3 & \\
\hline \multicolumn{9}{|l|}{ Age (years) } \\
\hline Mean \pm SD & $50.45 \pm 10.73$ & $49.59 \pm 10.44$ & $47.16 \pm 11.44$ & 0.001 & $46.91 \pm 11.2$ & $49.98 \pm 10.6$ & $50.34 \pm 9.87$ & 0.008 \\
\hline \multicolumn{9}{|l|}{ Gender \% } \\
\hline Males & 29.3 & 35.6 & 35.1 & \multirow{2}{*}{0.322} & 35.7 & 33.8 & 30.5 & \multirow{2}{*}{0.057} \\
\hline Females & 36.4 & 31.6 & 32.0 & & 31.5 & 33.0 & 35.5 & \\
\hline \multicolumn{9}{|l|}{ Marital status \% } \\
\hline Married & 33.3 & 33.3 & 33.3 & \multirow{2}{*}{0.299} & 33.2 & 33.2 & 33.6 & \multirow{2}{*}{0.927} \\
\hline Unmarried & 33.3 & 33.3 & 33.3 & & 38.5 & 38.5 & 23.0 & \\
\hline \multicolumn{9}{|l|}{ Educational level \% } \\
\hline Low education & 28.8 & 34.4 & 36.8 & \multirow{2}{*}{0.106} & 37.0 & 35.2 & 27.8 & \multirow{2}{*}{0.001} \\
\hline High education & 37.0 & 32.4 & 30.6 & & 30.3 & 31.8 & 37.9 & \\
\hline \multicolumn{9}{|l|}{ Employment history \% } \\
\hline Yes & 28.1 & 30.3 & 41.6 & 0.799 & 44.0 & 28.5 & 27.5 & 0.510 \\
\hline \multicolumn{9}{|l|}{ Family size \% } \\
\hline Less than five & 33.1 & 36.2 & 30.7 & \multirow{2}{*}{0.316} & 33.3 & 31.0 & 35.7 & \multirow{2}{*}{0.004} \\
\hline Five or more & 33.4 & 31.9 & 34.7 & & 33.3 & 34.6 & 32.1 & \\
\hline \multicolumn{9}{|c|}{ Monthly income (NIS) \% } \\
\hline$\leq 2000$ (NIS) & 32.0 & 34.0 & 34.0 & \multirow{2}{*}{0.027} & 33.6 & 33.2 & 33.2 & \multirow{2}{*}{0.001} \\
\hline$>2000$ (NIS) & 40.2 & 29.9 & 29.9 & & 31.4 & 34.3 & 34.3 & \\
\hline \multicolumn{9}{|l|}{ Enough income \% } \\
\hline Yes & 33.7 & 34.9 & 31.4 & 0.001 & 37.2 & 31.4 & 31.4 & 0.379 \\
\hline \multicolumn{9}{|l|}{ History of smoking \% } \\
\hline Yes & 42.3 & 33.8 & 23.9 & 0.030 & 21.2 & 40.8 & 38.0 & 0.902 \\
\hline Diabetes duration? & & & & & & & & \\
\hline Less than 5 years & 25.4 & 31.7 & 42.9 & & 43.9 & 26.0 & 30.1 & \\
\hline Five to ten years & 35.2 & 35.2 & 29.6 & 0.001 & 31.2 & 31.8 & 37.0 & 0.121 \\
\hline More than 10 years & 37.2 & 32.6 & 30.2 & & 28.0 & 40.5 & 31.5 & \\
\hline Female menopausal sta & & & & & & & & \\
\hline Premenopausal & 33.7 & 32.6 & 33.7 & & 37.2 & 33.7 & 29.1 & \\
\hline Postmenopausal & 37.6 & 31.2 & 31.2 & 0.001 & 28.7 & 32.6 & 38.7 & 0.074 \\
\hline Male & 29.3 & 35.6 & 35.1 & & 35.7 & 33.8 & 30.5 & \\
\hline Dietary supplement us & & & & & & & & \\
\hline Yes & 35.0 & 32.3 & 32.7 & 0.051 & 30.8 & 34.6 & 34.6 & 0.617 \\
\hline Waist circumference ( & & & & & & & & \\
\hline Mean \pm SD & $106.2 \pm 17.6$ & $105.4 \pm 17.4$ & $102.5 \pm 15.9$ & 0.001 & $101.9 \pm 17.1$ & $105.2 \pm 17.0$ & $106.6 \pm 17.4$ & 0.001 \\
\hline Body mass index $(\mathrm{kg} /$ & & & & & & & & \\
\hline Mean \pm SD & $30.67 \pm 5.8$ & $30.35 \pm 6.2$ & $30.11 \pm 6.2$ & 0.010 & $29.44 \pm 6.2$ & $30.13 \pm 5.8$ & $30.85 \pm 6.1$ & 0.007 \\
\hline Physical activity (Total & & & & & & & & \\
\hline Mean \pm SD & $1139.7 \pm 1362$ & $1244.0 \pm 1270$ & $1498.5 \pm 1621$ & 0.001 & $1487.2 \pm 1567$ & $1247.1 \pm 1418$ & $1173.0 \pm 1276$ & 0.001 \\
\hline
\end{tabular}

ANOVA test was used for quantitative variables and chi-square for qualitative variables. P value less than 0.05 was considered as statistically significant. SD, stander deviation. 
Table 5. Odd ratio and confidence interval for the depression scale across tertiles categories of dietary pattern scores.

\begin{tabular}{|c|c|c|c|c|c|c|c|c|c|}
\hline \multicolumn{5}{|c|}{ The Western pattern } & \multicolumn{5}{|c|}{ The grains-vegetables, and fruits pattern } \\
\hline T1 & $\mathrm{T} 2$ & T3 & $P$ value & OR $(95 \% \mathrm{CI})$ & T1 & $\mathrm{T} 2$ & T3 & $P$ value & OR $(95 \% \mathrm{CI})$ \\
\hline \multicolumn{10}{|c|}{ Depressed (Depression scale, 7 -items scores $\geq 10$ ) } \\
\hline \multirow[t]{2}{*}{30.5} & 33.9 & 35.6 & 0.783 & $1.030(0.836-1.267)$ & 31.4 & 33.0 & 35.6 & 0.198 & $0.874(0.712-1.073)$ \\
\hline & Adjusted ${ }^{*}$ & & 0.476 & $0.774(0.383-1.565)$ & & Adjusted ${ }^{*}$ & & 0.001 & $0.763(0.667-0.871)$ \\
\hline \multicolumn{10}{|c|}{ Healthy (Depression scale, 7 -items scores $<10$ ) } \\
\hline \multirow[t]{2}{*}{34.3} & 33.1 & 32.6 & 0.715 & $0.878(0.437-1.764)$ & 34.0 & 33.4 & 32.6 & 0.219 & $1.152(0.920-1.442)$ \\
\hline & Adjusted ${ }^{*}$ & & 0.137 & $0.207(0.026-1.650)$ & & Adjusted ${ }^{*}$ & & 0.004 & $1.443(1.131-1.839)$ \\
\hline
\end{tabular}

The OR and CI for depressed (Depression scale, 7-items scores $\geq 10$ ), and healthy (Depression scale, 7-items scores $<10$ ) across tertiles categories of dietary pattern scores were tested by binary logistic regression. ${ }^{*}$ Adjusted for age, educational level, family size, monthly income, enough income, history of smoking, diabetes duration, female menopausal status, WC $(\mathrm{cm}), \mathrm{BMI}\left(\mathrm{kg} / \mathrm{m}^{2}\right)$, and physical activity (Total MET). P value less than 0.05 was considered as statistically significant. OR, odds ratio; CI, confidence interval.

quality of life is very low, and daily life of Palestinians is constantly under threat which make Palestinians more vulnerable to stress and depression [4]. Sweileh et al. [4], show that the prevalence of depression was $40 \%$ among T2DM patients in north West-Bank of Palestine. Moreover, the data regarding the prevalence of depression among patients with T2DM in Gaza Strip are scarce, which made the comparison of our results with previous studies difficult. According to previous studies, the prevalence of depression in T2DM patients varies from 30 to 83 percent [31] [32]. The results of our study support these findings. In the current study, the high prevalence of depression may be related in part to the burden of living with DM and its complications which may plays an important role in the etiology of depression [33]. Furthermore, the duration of DM is also associated with development of depression in this study (35.8\% of the patients had DM for more than 10 years), and has been reported by other researchers as well [34]. Increased duration of DM is known to significantly increase the risk of developing complications and health care expenditures; as a result, such patients are more prone to develop psychological illnesses [35]. Moreover, the exact mechanisms underlying the relationship between depression and DM have not been established yet [36]. Suggested mechanisms by which anxiety and depression increased the risk of DM are alterations in insulin signaling in the brain, activation of proinflammatory pathways, or distress-induced up regulation of counter regulatory hormone systems like glucocorticoid [37] [38], which could impair insulin sensitivity. Another possible mechanism may be related to the effect of depression on behaviors and lifestyle. It has been shown that depressed persons are more likely to be physically inactive and central or general obese and have unhealthy eating habits, poor diet, and sedentary lifestyle [39], which is associated with increased risk of coronary heart diseases and DM. Additionally, our results showed that the depression is more prevalent among women (58.3\%) than among men (41.7\%) which is a common finding in previous studies [40] [41]. This is may be due to that, women is influenced by adverse experiences, sociocultural roles, psychological attributes, biological factors including hormones 
and poor social support, allows them to be more emotional and extroversive in nature, in comparison to men [42] [43].

On the other hand, in the present study two major dietary patterns were identified by factor analysis: 1) The Western dietary pattern characterized by a high intake of refined grains, red meat, organ meat, fast foods, eggs, high-fat dairy products, hydrogenated fats, sugar, sweets \& desserts, snacks, and soft drinks as well as a low intake of beans and legumes; 2) The grains-vegetables, and fruits dietary pattern characterized by a high intake of whole grains, potatoes, vegetables, tomatoes, fruits, vegetable oils, olive, and beverages. The main findings of this study indicate that, after adjusting for the potential confounders, patients in the lowest tertile (T1) of the grains-vegetables, and fruits dietary pattern had a lower odds for depression; where as a higher odds for healthy. In fact, limited studies were found in the literature to evaluate the relationship between dietary patterns and depression among T2DM patients. Most studies have examined the associations between individual foods or food groups and nutrients and depression [21] [22], instead of focusing on dietary patterns, which is the most sensible approach to test the role of the overall diet on nutrition-related diseases. Although dietary patterns and diet quality are a novel area of attention in the lifestyle-mental health research field, there is no study in this field among DM patients.

The grains-vegetables, and fruits dietary pattern in our study may be associated with a lower prevalence of depression; where as a higher odds for healthy. No significant association was found between the Western dietary pattern with depression. Akbaraly et al. [44], in a cohort study showed that whole food pattern characterized by a high intake of vegetables, fruits, and fish was inversely associated with depression, while processed food pattern characterized by a high intake of sweetened desserts, fried food, processed meat, refined grains, and high-fat dairy products showed a direct association with depression. In this population, the prevalence of DM was significantly higher among depressed persons compared with non-depressed ones [44]. In another study, Baharzadeh et al. [2], show that, a high intake of total fruits-vegetables, total vegetables, total fruits, citrus, other fruits and green leafy vegetables was independently related to a lower odds of depression. Additionally, Liu X. et al. [45], in a meta-analysis study indicated that intakes of both fruits and vegetables were inversely related to the risk of depression. The results of our study support these findings. Several studies showed higher consumption of unhealthy foods and lower consumption of fruits and vegetables in depressed mood [46]. Sánchez-Villegas et al. [47], demonstrated an inverse relationship between the adherence to Mediterranean diet and depression, while consumption of fast foods and commercial baked goods increased the risk of depression among Spanish. Contrary to these studies, another study among Japanese did not show any significant association between depression and various dietary patterns [48].

In our study, the inverse association between the grains-vegetables, and fruits 
pattern with depression could be attributed to pattern's healthy ingredients including micronutrients, phytochemicals, antioxidants, vitamins, dietary fibers, magnesium and anti-infammatory components. These nutrients have been independently associated with reduced risks of depression [49]. Antioxidants such as carotenoids, vitamin $\mathrm{C}$, and vitamin $\mathrm{E}$ might prevent depressive symptoms [50]. High intake of B vitamins such as folic acid has been associated with lower risk of depression [51]. Fruits and vegetables also supplies dietary fiber whose role in improving mood has been suggested [52]. Green leafy vegetables are good sources of folate and magnesium, which are important in the prevention of depression [53]. Folate is involved in the metabolism of monoamines such as serotonin in the brain [54]. Reduced synthesis of serotonin results to depressed mood [55]. In magnesium deficiency, high levels of calcium and glutamate reduce synaptic function and lead to depression [56]. In addition, lower levels of C-reactive protein, a marker of low-grade inflammation, has been reported in magnesium sufficiency [57]. In our study, the grains-vegetables, and fruits pattern has been shown to be the healthiest dietary pattern and is quite close to that diet, which generally recommended as a healthy dietary pattern with low in animal foods, saturated fat, trans fat, cholesterol and simple sugar, which may be associated with a higher risks of diabetes and depression [58]. Actually, the relationship between dietary patterns with depression among T2DM patients need more studies in the future. The main limitations of this study is its cross sectional design; the causal relationship could not be determined, and it limits the generalizability of our results. In addition, the possibility of recall bias and misreporting by using FFQ assessment of dietary patterns are other limitations. The main strength of our study was its being the first study, which shows the dietary patterns among T2DM patients and its association with depression in Gaza Strip, Palestine, and its large sample size.

\section{Conclusion}

We conclude that, the grains-vegetables, and fruits dietary pattern may be associated with a lower prevalence of depression, and has been shown to be the healthiest dietary pattern among T2DM patients. Further future studies are required to confirm these findings.

\section{Ethics Approval and Consent to Participate}

The study protocol was approved by the Ethics Committee of Tehran University of Medical Sciences (Code: IR.TUMS.REC.1394.58) and by the Palestinian Health Research Council (Helsinki Ethical Committee of Research PHRC/HC/60/15). In addition, written informed consent was also obtained from each participant.

\section{Consent for Publication}

Not applicable. 


\section{Availability of Data and Material}

The datasets used and/or analyzed during the current study are available from the corresponding author on reasonable request.

\section{Funding}

This research did not receive any specific grant from funding agencies in the public, commercial, or not-for-profit sectors.

\section{Authors' Contributions}

AHB, MS, AA and HF participated in the design of the study, data collection, performed the statistical analysis and drafted the manuscript. KD and AHB supervised the study and participated in draft review. All authors have read and approved the final version of the manuscript and agree with the order of presentation of the authors.

\section{Acknowledgements}

The authors thank the staff and participants in the Palestinian Ministry of Health, PHCs for their important contributions to the study.

\section{Competing Interests}

The authors declare that they have no competing interests.

\section{References}

[1] Greden, J.F. (2003) Physical Symptoms of Depression: Unmet Needs. The Journal of Clinical Psychiatry, 64, 5-11.

[2] Baharzadeh, E., Siassi, F., Qorbani, M., Koohdani, F., Pak, N. and Sotoudeh, G. (2018) Fruits and Vegetables Intake and Its Subgroups Are Related to Depression: A Cross-Sectional Study from a Developing Country. Annals of General Psychiatry, 17, 46. https://doi.org/10.1186/s12991-018-0216-0

[3] Michaud, C.M., Murray, C.J. and Bloom, B.R. (2001) Burden of Disease-Implications for Future Research. JAMA, 285, 535-539. https://doi.org/10.1001/jama.285.5.535

[4] Sweileh, W.M., Abu-Hadeed, H.M., Al-Jabi, S.W. and Sa'ed, H.Z. (2014) Prevalence of Depression among People with Type 2 Diabetes Mellitus: A Cross Sectional Study in Palestine. BMC Public Health, 14, 163. https://doi.org/10.1186/1471-2458-14-163

[5] Haghighatdoost, F. and Azadbakht, L. (2013) Dietary Treatment Options for Depression among Diabetic Patient, Focusing on Macronutrients. Journal of Diabetes Research, 2013, Article ID: 421832. https://doi.org/10.1155/2013/421832

[6] El-Shafie, T.M., El-Saghier, E.O.A. and Ramadan, I.K. (2011) Depression among Type 2 Diabetic Patients. Egyptian Journal of Hospital Medicine, 44, 1-28.

[7] Grisel, J.E., Rasmussen, R. and Sperry, L. (2006) Anxiety and Depression: Physiological and Pharmacological Considerations. Journal of Individual Psychology, 62.

[8] Anderson, R.J., Freedland, K.E., Clouse, R.E. and Lustman, J. (2001) The Prevalence of Comorbid Depression in Adults with Diabetes: A Meta-Analysis. Diabetes Care, 24, 1069-1078. https://doi.org/10.2337/diacare.24.6.1069 
[9] Lustman, J. and Harper, G.W. (1987) Nonpsychiatric Physicians' Identification and Treatment of Depression in Patients with Diabetes. Comprehensive Psychiatry, 28, 22-27. https://doi.org/10.1016/0010-440X(87)90040-X

[10] El Bilbeisi, A.H., Hosseini, S. and Djafarian, K. (2018) Prevalence of Metabolic Syndrome and Its Components Using Two Proposed Criteria among Patients with Type 2 Diabetes in Gaza Strip, Palestine. BAOJ Nutrition, 4, 054.

[11] El Bilbeisi, A.H., Hosseini, S. and Djafarian, K. (2017) Dietary Patterns and Metabolic Syndrome among Type 2 Diabetes Patients in Gaza Strip, Palestine. Ethiopian Journal of Health Sciences, 27, 227-238. https://doi.org/10.4314/ejhs.v27i3.4

[12] El Bilbeisi, A.H., Hosseini, S. and Djafarian, K. (2017) Association of Dietary Patterns with Diabetes Complications among Type 2 Diabetes Patients in Gaza Strip, Palestine: A Cross Sectional Study. Journal of Health, Population and Nutrition, 36, 37. https://doi.org/10.1186/s41043-017-0115-Z

[13] Relief, U.N. (2007) Works Agency. Annual Report of the Department of Health. United Nations Relief and Works Agency, Amman.

[14] Abu-Rmeileh, N.M., Husseini, A., O’Flaherty, M., Shoaibi, A. and Capewell, S. (2012) Forecasting Prevalence of Type 2 Diabetes Mellitus in Palestinians to 2030: Validation of a Predictive Model. The Lancet, 380, S21. https://doi.org/10.1016/S0140-6736(13)60202-0

[15] El Bilbeisi, A.H., Hosseini, S. and Djafarian, K. (2018) Dietary Patterns and Their Association with Blood Pressure Control among Hypertensive Patients in Gaza Strip, Palestine. Journal of Family Medicine and Health Care, 4, 5-12. https://doi.org/10.11648/j.jfmhc.20180402.11

[16] Newby, K. and Tucker, K.L. (2004) Empirically Derived Eating Patterns Using Factor or Cluster Analysis: A Review. Nutrition Reviews, 62, 177-203. https://doi.org/10.1111/j.1753-4887.2004.tb00040.x

[17] Díaz-López, A., Babio, N., Martínez-González, M.A., Corella, D., Amor, A.J., Fitó, M., Estruch, R., Arós, F., Gómez-Gracia, E., Fiol, M. and Lapetra, J. (2015) Mediterranean Diet, Retinopathy, Nephropathy, and Microvascular Diabetes Complications: A Post Hoc Analysis of a Randomized Trial. Diabetes Care, dc151117. https://doi.org/10.2337/dc15-1117

[18] Gonzalez, J.S., Safren, S.A., Delahanty, L.M., Cagliero, E., Wexler, D.J., Meigs, J.B. and Grant, R.W. (2008) Symptoms of Depression Prospectively Predict Poorer Self-Care in Patients with Type 2 Diabetes. Diabetic Medicine, 25, 1102-1107. https://doi.org/10.1111/j.1464-5491.2008.02535.x

[19] Ciarambino, T., Ferrara, N., Castellino, Paolisso, G., Coppola, L. and Giordano, M. (2011) Effects of a 6-Days-a-Week Low Protein Diet Regimen on Depressive Symptoms in Young-Old Type 2 Diabetic Patients. Nutrition, 27, 46-49. https://doi.org/10.1016/j.nut.2009.10.017

[20] Ciarambino, T., Castellino, Paolisso, G., Coppola, L., Ferrara, N., Signoriello, G. and Giordano, M. (2012) Long Term Effects of Low Protein Diet on Depressive Symptoms and Quality of Life in Elderly Type 2 Diabetic Patients. Clinical Nephrology, 78, 122-128. https://doi.org/10.5414/CN107279

[21] Rosenthal, N.E., Genhart, M.J., Caballero, B., Jacobsen, F.M., Skwerer, R.G., Coursey, R.D., Rogers, S. and Spring, B.J. (1989) Psychobiological Effects of Carbohydrate- and Protein-Rich Meals in Patients with Seasonal Affective Disorder and Normal Controls. Biological Psychiatry, 25, 1029-1040. https://doi.org/10.1016/0006-3223(89)90291-6

[22] Timonen, M., Horrobin, D., Jokelainen, J., Laitinen, J., Herva, A. and Räsänen 
(2004) Fish Consumption and Depression: The Northern Finland 1966 Birth Cohort Study. Journal of Affective Disorders, 82, 447-452. https://doi.org/10.1016/j.jad.2004.02.002

[23] El Bilbeisi, A.H., Hosseini, S. and Djafarian, K. (2017) The Association between Physical Activity and the Metabolic Syndrome among Type 2 Diabetes Patients in Gaza Strip, Palestine. Ethiopian Journal of Health Sciences, 27, 273-282. https://doi.org/10.4314/ejhs.v27i3.9

[24] Hamdan, M., Monteagudo, C., Lorenzo-Tovar, M.L., Tur, J.A., Olea-Serrano, F. and Mariscal-Arcas, M. (2014) Development and Validation of a Nutritional Questionnaire for the Palestine Population. Public Health Nutrition, 17, 2512-2518. https://doi.org/10.1017/S1368980013002711

[25] Afzali, A., Delavar, A., Borjali, A. and Mirzamani, M. (2007) Psychometric Properties of DASS-42 as Assessed in a Sample of Kermanshah High School Students. Journal of Research in Behavioural Sciences, 5, 81-92.

[26] Lovibond, S.H. and Lovibond, P.F. (1995) Manual for the Depression Anxiety Stress Scale. The Psychological Foundation of Australia, Sydney.

https://doi.org/10.1037/t01004-000

[27] Farag, H.A.M., Hosseinzadeh-Attar, M.J., Muhammad, B.A., Esmaillzadeh, A. and El Bilbeisi, A.H. (2018) Comparative Effects of Vitamin D and Vitamin C Supplementations with and without Endurance Physical Activity on Metabolic Syndrome Patients: A Randomized Controlled Trial. Diabetology \& Metabolic Syndrome, 10, 80. https://doi.org/10.1186/s13098-018-0384-8

[28] Abdollahi, S., Zeinali, F., Azam, K., Toupchian, O. and Djafarian, K. (2015) Identifying Major Dietary Patterns among the Elderly in Tehran Health Homes. Jundishapur Journal of Health Sciences, 7, e30395. https://doi.org/10.17795/jjhs-30395

[29] Hosseyni Esfahani, F., Jazayeri, A., Mirmiran, Mehrabi, Y. and Azizi, F. (2008) Dietary Patterns and Their Association with Socio-Demographic and Lifestyle Factors among Thehrani Adults: Tehran Lipid and Glucose Study. Journal of School of Public Health \& Institute of Public Health Research, 6, 23-36.

[30] Esmaeillzadeh, A., Azadbakht, L., Khoshfetrat, M.R. and Kimiagar, M. (2011) Major Dietary Patterns, General and Central Adiposity among Tehrani Female Teachers. 676-689.

[31] Das, R., Singh, O., Thakurta, R.G., Khandakar, M.R., Ali, S.N., Mallick, A.K., Roy, P. and Bhattacharrya, A.K. (2013) Prevalence of Depression in Patients with Type II Diabetes Mellitus and Its Impact on Quality of Life. Indian Journal of Psychological Medicine, 35, 284. https://doi.org/10.4103/0253-7176.119502

[32] Raval, A., Dhanaraj, E., Bhansali, A., Grover, S. and Tiwari (2010) Prevalence \& Determinants of Depression in Type 2 Diabetes Patients in a Tertiary Care Centre. Indian Journal of Medical Research, 132, 195.

[33] Lin, E.H., Rutter, C.M., Katon, W., Heckbert, S.R., Ciechanowski, Oliver, M.M., Ludman, E.J., Young, B.A., Williams, L.H., McCulloch, D.K. and Von Korff, M. (2010) Depression and Advanced Complications of Diabetes: A Prospective Cohort Study. Diabetes Care, 33, 264-269. https://doi.org/10.2337/dc09-1068

[34] Khuwaja, A.K., Lalani, S., Dhanani, R., Azam, I.S., Rafique, G. and White, F. (2010) Anxiety and Depression among Outpatients with Type 2 Diabetes: A Multi-Centre Study of Prevalence and Associated Factors. Diabetology \& Metabolic Syndrome, 2, 72. https://doi.org/10.1186/1758-5996-2-72

[35] Seuring, T., Archangelidi, O. and Suhrcke, M. (2015) The Economic Costs of Type 2 Diabetes: A Global Systematic Review. Pharmacoeconomics, 33, 811-831. 
https://doi.org/10.1007/s40273-015-0268-9

[36] De Groot, M., Anderson, R., Freedland, K.E., Clouse, R.E. and Lustman, J. (2001) Association of Depression and Diabetes Complications: A Meta-Analysis. Psychosomatic Medicine, 63, 619-630. https://doi.org/10.1097/00006842-200107000-00015

[37] Munhoz, C.D., Sorrells, S.F., Caso, J.R., Scavone, C. and Sapolsky, R.M. (2010) Glucocorticoids Exacerbate Lipopolysaccharide-Induced Signaling in the Frontal Cortex and Hippocampus in a Dose-Dependent Manner. Journal of Neuroscience, 30, 13690-13698. https://doi.org/10.1523/JNEUROSCI.0303-09.2010

[38] Kabe, Y., Ando, K., Hirao, S., Yoshida, M. and Handa, H. (2005) Redox Regulation of NF- $\kappa$ B Activation: Distinct Redox Regulation between the Cytoplasm and the Nucleus. Antioxidants \& Redox Signaling, 7, 395-403.

https://doi.org/10.1089/ars.2005.7.395

[39] Wyatt, S.B., Winters, K.P. and Dubbert, M. (2006) Overweight and Obesity: Prevalence, Consequences, and Causes of a Growing Public Health Problem. The American Journal of the Medical Sciences, 331, 166-174. https://doi.org/10.1097/00000441-200604000-00002

[40] Kuehner, C. (2017) Why Is Depression More Common among Women than among Men? The Lancet Psychiatry, 4, 146-158. https://doi.org/10.1016/S2215-0366(16)30263-2

[41] Kessler, R.C. (2003) Epidemiology of Women and Depression. Journal of Affective Disorders, 74, 5-13. https://doi.org/10.1016/S0165-0327(02)00426-3

[42] Dennerstein, L., Astbury, J., Morse, C. and World Health Organization (1993) Psychosocial and Mental Health Aspects of Women's Health.

[43] Kendler, K.S., Neale, M.C., Kessler, R.C., Heath, A.C. and Eaves, L.J. (1993) A Longitudinal Twin Study of Personality and Major Depression in Women. Archives of General Psychiatry, 50, 853-862. https://doi.org/10.1001/archpsyc.1993.01820230023002

[44] Akbaraly, T.N., Brunner, E.J., Ferrie, J.E., Marmot, M.G., Kivimaki, M. and Singh-Manoux, A. (2009) Dietary Pattern and Depressive Symptoms in Middle Age. The British Journal of Psychiatry, 195, 408-413. https://doi.org/10.1192/bjp.bp.108.058925

[45] Liu, X., Yan, Y., Li, F. and Zhang, D. (2016) Fruit and Vegetable Consumption and the Risk of Depression: A Meta-Analysis. Nutrition, 32, 296-302. https://doi.org/10.1016/j.nut.2015.09.009

[46] Jacka, F.N., Kremer, J., Leslie, E.R., Berk, M., Patton, G.C., Toumbourou, J.W. and Williams, J.W. (2010) Associations between Diet Quality and Depressed Mood in Adolescents: Results from the Australian Healthy Neighbourhoods Study. Australian and New Zealand Journal of Psychiatry, 44, 435-442. https://doi.org/10.3109/00048670903571598

[47] Sánchez-Villegas, A., Toledo, E., de Irala, J., Ruiz-Canela, M., Pla-Vidal, J. and Martínez-González, M.A. (2012) Fast-Food and Commercial Baked Goods Consumption and the Risk of Depression. Public Health Nutrition, 15, 424-432. https://doi.org/10.1017/S1368980011001856

[48] Nanri, A., Mizoue, T., Matsushita, Y., Sasaki, S., Ohta, M., Sato, M. and Mishima, N. (2010) Serum Folate and Homocysteine and Depressive Symptoms among Japanese Men and Women. European Journal of Clinical Nutrition, 64, 289. https://doi.org/10.1038/ejcn.2009.143

[49] Muraki, I., Imamura, F., Manson, J.E., Hu, F.B., Willett, W.C., van Dam, R.M. and 
Sun, Q. (2013) Fruit Consumption and Risk of Type 2 Diabetes: Results from Three Prospective Longitudinal Cohort Studies. BMJ, 347, f5001. https://doi.org/10.1136/bmj.f5001

[50] Mihrshahi, S., Dobson, A.J. and Mishra, G.D. (2015) Fruit and Vegetable Consumption and Prevalence and Incidence of Depressive Symptoms in Mid-Age Women: Results from the Australian Longitudinal Study on Women's Health. European Journal of Clinical Nutrition, 69, 585. https://doi.org/10.1038/ejcn.2014.222

[51] Skarupski, K.A., Tangney, C., Li, H., Ouyang, B., Evans, D.A. and Morris, M.C. (2010) Longitudinal Association of Vitamin B-6, Folate, and Vitamin B-12 with Depressive Symptoms among Older Adults over Time. The American Journal of Clinical Nutrition, 92, 330-335. https://doi.org/10.3945/ajen.2010.29413

[52] Eby, G.A. and Eby, K.L. (2006) Rapid Recovery from Major Depression Using Magnesium Treatment. Medical Hypotheses, 67, 362-370.

https://doi.org/10.1016/j.mehy.2006.01.047

[53] Mamplekou, E., Bountziouka, V., Psaltopoulou, T., Zeimbekis, A., Tsakoundakis, N., Papaerakleous, N., Gotsis, E., Metallinos, G., Pounis, G., Polychronopoulos, E. and Lionis, C. (2010) Urban Environment, Physical Inactivity and Unhealthy Dietary Habits Correlate to Depression among Elderly Living in Eastern Mediterranean Islands: The MEDIS (Mediterranean Islands Elderly) Study. The Journal of Nutrition, Health \& Aging, 14, 449-455. https://doi.org/10.1007/s12603-010-0091-0

[54] Chi, S.H., Wang, J.Y. and Tsai, A.C. (2016) Combined Association of Leisure-Time Physical Activity and Fruit and Vegetable Consumption with Depressive Symptoms in Older Taiwanese: Results of a National Cohort Study. Geriatrics \& Gerontology International, 16, 244-251. https://doi.org/10.1111/ggi.12459

[55] Mayeux, R., Stern, Y., Cote, L. and Williams, J.B. (1984) Altered Serotonin Metabolism in Depressed Patients with Parkinson's Disease. Neurology, 34, 642-642. https://doi.org/10.1212/WNL.34.5.642

[56] Tarleton, E.K., Littenberg, B., MacLean, C.D., Kennedy, A.G. and Daley, C. (2017) Role of Magnesium Supplementation in the Treatment of Depression: A Randomized Clinical Trial. PLoS ONE, 12, e0180067. https://doi.org/10.1371/journal.pone.0180067

[57] Howren, M.B., Lamkin, D.M. and Suls, J. (2009) Associations of Depression with C-Reactive Protein, IL-1, and IL-6: A Meta-Analysis. Psychosomatic Medicine, 71, 171-186. https://doi.org/10.1097/PSY.0b013e3181907clb

[58] Dipnall, J.F., Pasco, J.A., Meyer, D., Berk, M., Williams, L.J., Dodd, S. and Jacka, F.N. (2015) The Association between Dietary Patterns, Diabetes and Depression. Journal of Affective Disorders, 174, 215-224. https://doi.org/10.1016/j.jad.2014.11.030 


\section{Abbreviations}

DASS: Depression, anxiety, stress scales;

SPSS: Statistical package for the social sciences;

T: Tertile;

OR: Odds ratio;

$\mathrm{CI}$ : Confidence interval;

DM: Diabetes mellitus;

T2DM: Type 2 diabetes mellitus;

PHCs: Primary health care centers;

FFQ: Food frequency questionnaire;

WC: Waist circumference;

BMI: Body mass index;

IPAQ: International physical activity questionnaire;

MET: Metabolic equivalents. 